\title{
Steady-state thermal analysis of an innovative receiver for linear Fresnel reflectors
}

\author{
R. Abbas*, J. Muñoz, J.M. Martínez-Val
}

\begin{abstract}
A B S T R A C T
The study of the performance of an innovative receiver for linear Fresnel reflectors is carried out in this paper, and the results are analyzed with a physics perspective of the process. The receiver consists of a bundle of tubes parallel to the mirror arrays, resulting on a smaller cross section for the same receiver width as the number of tubes increases, due to the diminution of their diameter. This implies higher heat carrier fluid speeds, and thus, a more effective heat transfer process, although it conveys higher pumping power as well. Mass flow is optimized for different tubes diameters, different impinging radiation intensities and different fluid inlet temperatures. It is found that the best receiver design, namely the tubes diameter that maximizes the exergetic efficiency for given working conditions, is similar for the cases studied. There is a range of tubes diameters that imply similar efficiencies, which can drive to capital cost reduction thanks to the flexibility of design. In addition, the length of the receiver is also optimized, and it is observed that the optimal length is similar for the working conditions considered. As a result of this study, it is found that this innovative receiver provides an optimum design for the whole day, even though impinging radiation intensity varies notably. Thermal features of this type of receiver could be the base of a new generation of concentrated solar power plants with a great potential for cost reduction, because of the simplicity of the system and the lower weigh of the components, plus the flexibility of using the receiver tubes for different streams of the heat carrier fluid.
\end{abstract}

\section{Introduction and background}

Concentrated Solar Power (CSP) may play a major role in the future energy mix, especially in countries with a very high annual global direct irradiation, where it seems to be a more cost-effective technology than photovoltaics for electricity generation [1]. Nevertheless, it is still not a mature technology, even though $354 \mathrm{MW}$ were installed in Mojave Desert during the 1980s and 1990s [2].

There are many possible configurations for CSP, such as parabolic dish, linear Fresnel, parabolic trough and central receiver; several relevant books and articles explain the main features of such technologies [2-9]. The choice of the technology has a deep impact on the solar concentration achieved, which is one of the critical parameters in the design of a solar thermal power unit $[3,10,11]$.

Muñoz et al. [12] have proven that, for each heat carrier fluid temperature, the dependence of the energetic efficiency on the concentration factor shows two regimes, thus appearing a threshold. When the radiation flux is lower than the value given by the threshold, the efficiency drops to zero very fast; but, if the concentration is augmented over the threshold, there is not an important efficiency increase due to a saturation effect.
Unlike the thermodynamic cycle efficiency, which increases as the temperature of the heat source does, the efficiency of thermal energy absorption by the heat carrier fluid decreases as its outlet temperature augments. As a result, the overall efficiency might be maximized at a given temperature $[13,14]$, which depends on the receiver's technology due to materials limitation. For linear receivers, i.e. parabolic trough and Fresnel arrays, the receiver's selective coating and the heat carrier fluid itself have traditionally been the temperature limiting elements.

The selective coating is the outermost coat of material on the receiver, with high absorptivity for solar radiation and very low emissivity for the infrared spectrum. This element has a great effect on the receiver efficiency, and much research has been done to improve it since the end of the 1970s [15-17]. Thanks to this research, the maximum working temperature has been increased up to $550^{\circ} \mathrm{C}[18]$, not being anymore the limiting temperature element in linear receivers.

The heat carrier fluid is the component that flows through the receiver, absorbs the heat, and carries it to the power block. Many advances have been achieved lately on direct steam generation for linear receivers [19-21], but thermal oils are still the main technology in use. This is mainly due to the difficulties found to generate steam on a horizontal tube and the heat transfer coefficient variation when the vapor quality changes, which may generate serious problems on transient regimes. In addition, oils have a good heat 


\section{Nomenclature}

A heat exchange surface with the fluid $\left(\mathrm{m}^{2}\right)$

$C_{f} \quad$ Carnot coefficient (-)

$D_{e} \quad$ tubes outermost diameter $(\mathrm{m})$

$D_{i} \quad$ tubes innermost diameter $(\mathrm{m})$

$G_{f} \quad$ geometry factor of an intermediate heat exchanger (-)

$L \quad$ collector length $(\mathrm{m})$

$\mathrm{Nu} \quad$ Nusselt number $(-)$

$\Delta P \quad$ pressure drop along the circuit $(\mathrm{Pa})$

$\operatorname{Pr} \quad$ Prandtl number $(-)$

$\dot{Q}_{\text {gain }} \quad$ thermal power gained by the heat transfer fluid (W)

$\dot{Q}_{\text {sun }} \quad$ thermal power impinging onto the receiver $(W)$

$R_{\text {cond }}$ thermal resistance for conduction across the tubes $\left(\mathrm{m}^{2}\right.$ $\mathrm{K} / \mathrm{W}$ )

$R_{\text {conv }}$ thermal resistance for convection from the inner surface of the tubes to the fluid $\left(\mathrm{m}^{2} \mathrm{~K} / \mathrm{W}\right)$

$R_{\text {loss }} \quad$ thermal resistance from the outer surface of the receiver tubes to the environment $\left(\mathrm{m}^{2} \mathrm{~K} / \mathrm{W}\right)$

Re Reynolds number (-)

$T_{\text {air }} \quad$ environment temperature $(\mathrm{K})$

$T_{\text {in }} \quad$ fluid inlet temperature $\left({ }^{\circ} \mathrm{C}\right)$

$T_{\text {out }} \quad$ fluid outlet temperature $\left({ }^{\circ} \mathrm{C}\right)$
$T_{\text {sun }} \quad$ sun equivalent temperature $(\mathrm{K})$

$\Delta T \quad$ fluid temperature increase along the receiver $\left({ }^{\circ} \mathrm{C}\right)$

$\Delta T_{l m} \quad$ log mean temperature difference in the convection process $\left({ }^{\circ} \mathrm{C}\right)$

$U$ global coefficient for thermal losses from the receiver $\left(\mathrm{W} / \mathrm{m}^{2} \mathrm{~K}\right)$

W receiver width $(\mathrm{m})$

$\dot{W}_{p} \quad$ pumping power $(\mathrm{W})$

$c_{p} \quad$ specific heat capacity $(\mathrm{J} / \mathrm{kg} \mathrm{K})$

$f \quad$ friction coefficient $(-)$

$h \quad$ heat transfer coefficient to the fluid $\left(\mathrm{W} / \mathrm{m}^{2} \mathrm{~K}\right)$

$k$ thermal conductivity of the fluid [W/m-K]

$\dot{m} \quad$ fluid mass flow $(\mathrm{kg} / \mathrm{s})$

$n \quad$ number of tubes $(-)$

$q_{\text {sun }} \quad$ thermal power intensity impinging onto the receiver $\left(\mathrm{W} / \mathrm{m}^{2}\right)$

$v \quad$ fluid speed within the tubes $(\mathrm{m} / \mathrm{s})$

$\eta_{e x} \quad$ exergy efficiency (\%)

$\eta_{\text {th }} \quad$ energy efficiency (\%)

$\rho \quad$ fluid density $\left(\mathrm{kg} / \mathrm{m}^{3}\right)$ transfer coefficient and low pumping losses at adequate temperatures, and they have been widely used in the industry, even though oils cannot achieve ultra high temperatures. In the case of the Therminol VP1, an artificial oil traditionally used in parabolic trough solar power plants, the maximum temperature achievable is bellow $400^{\circ} \mathrm{C}[22]$, being the limiting temperature element at current time. The possibility of using other fluids for cooling the receiver, such as gas and molten salts, has also been addressed at a very preliminary stage.

Over this background, a full design window analysis of the steady-state thermal performance is carried out in this paper to identify the main features and the optimum working conditions of the receiver for different concentrated radiation fluxes (in $\mathrm{W} / \mathrm{m}^{2}$ ). For doing so, a linear receiver model has been developed to simulate an innovative Fresnel receiver that consists of multiple parallel tubes [23]. From this model, the fluid outlet temperature and thermal and exergetic efficiencies are obtained for different values of the definition variables (inlet temperature, thermal flux onto the receiver, number of tubes, fluid speed, etc.) and the inner variables (global thermal transfer coefficient, thermal transfer surface, etc).

The main outcome of the analysis is the identification of the best receiver design in terms of the tubes diameter, the length, the fluid mass flow and the inlet temperature, all depending on the concentration ratio.

In next section, the receiver model is explained, introducing all variables used in the model and establishing some guidelines to follow a systematic analysis. In Section 3, a study of the collector performance, depending on the mass flow, the inlet temperature and the tubes diameter, is presented for different impinging radiations onto the receiver, which has a great importance on the thermal performance. The results of this study are analyzed with a physics perspective in Section 4. This leads to the identification, in Section 5, of the elements that have a relevant role in defining a suitable design window for Fresnel receivers, and in optimizing their performance. Finally, the conclusions are discussed in last section, and the future work is identified for assembling a simple but efficient LFR receiver, as the basis of a new family of CSP plants.

\section{Model and design window definition for a multitube Fresnel receiver}

Many possible configurations for Fresnel collectors are found in the literature [6,23-29], but the one designed by Martínez-Val [23], see Fig. 1, seems to have important advantages compared to others: higher efficiency in driving the captured heat into the heat carrier fluid, and flexibility of design to accommodate the number of tubes to the thermal and hydraulic requirements of a given case. This has driven the present study to assume the use of the cited receiver, the tubes being made out of steel for cost reduction reasons, and the radiation absorbing screen being thermally connected to them. The tubes diameter is a fundamental parameter in the thermal performance of the receiver, as will be seen in the following sections.

Fresnel receivers require wide windows due to both, the distance from the furthest mirrors and the reflected radiation aperture, which is always larger than the sun light aperture (16' of cone half-angle). Therefore, vacuum inside the receiver box would imply very high mechanical stresses in the glass, not being advised; instead, an inert gas at approximately $1 \mathrm{~atm}$ is used in order to compensate the pressure and minimize window failure risks.

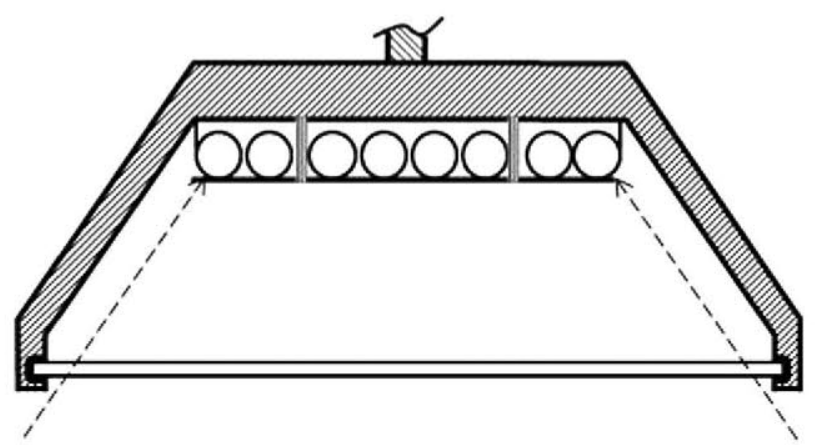

Fig. 1. Cross section of a multitube linear Fresnel receiver [23]. 
Thanks to the innovative design of this receiver, the pressure may be kept constant at atmospheric conditions, even if the temperature in the box changes along the day. The drawback to the use of a gas at atmospheric pressure is an increase in thermal losses with respect to a vacuum receiver.

A model that takes into account all relevant heat transfer processes has been developed on Engineering Equation Solver [30]. Similar models had been previously applied to parabolic trough collectors [31], solar boilers [9] and Fresnel devices [12]. The model used in this work had been previously used by the authors [9,12], and is based on a model created for trough collectors by Forristall [31]. Such model was validated with experimental results of the Aztrak plant, on a LS-2 collector [32,33]. These technical reports indicate errors of the model compared to the results of less than $2 \%$.

The thermal behavior of the receiver is self-consistently governed by:

- The heat transfer equation, which is of the type of an intermediate heat exchanger:

$$
\dot{Q}_{\text {gain }}=G_{f} \cdot h \cdot A \cdot \Delta T_{l m} .
$$

- The thermodynamic equation of the fluid, which undergoes an increase in specific enthalpy:

$$
\dot{Q}_{\text {gain }}=c_{p} \cdot \dot{m} \cdot \Delta T \text {. }
$$

- The hydraulic equation, which imposes the requirement of pumping power to overcome the pressure drop associated to the fluid motion:

$$
\dot{W}_{p}=\frac{\dot{m}}{\rho} \Delta P
$$

In previous equations, $\dot{Q}_{\text {gain }}$ refers to the thermal power gained by the heat transfer fluid, $G_{f}$ to the geometry factor of an intermediate heat exchanger - which is in this case close to one due to the similarity between the receiver behavior and an intermediate heat

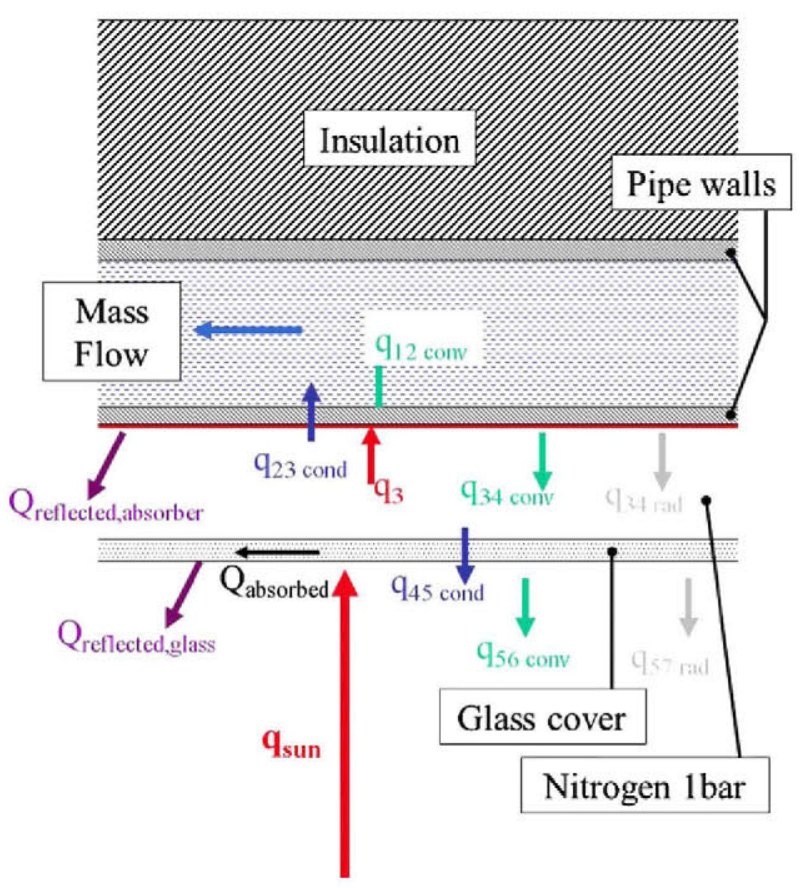

Fig. 2. Thermal fluxes involved in linear receivers [12]. exchanger-, $h$ to the heat transfer coefficient, $A$ to the heat exchange surface, $\Delta T_{l m}$ to the log mean temperature difference along the receiver, $c_{p}$ to its specific heat, $\dot{m}$ to the mass flow, $\Delta T=T_{o}-T_{i}$ to the fluid temperature increase, $\dot{W}_{p}$ to the pumping power, $\rho$ to the fluid density and $\Delta P$ to the pressure drop along the circuit.

Relevant heat transfer processes are depicted in Fig. 2, where the numbers are labels for the following elements:

(1) Heat transfer fluid

(2) Pipe inner surface

(3) Pipe outer surface - selective coating

(4) Glass cover inner surface

(5) Glass cover outer surface

(6) Air

(7) Environment.

In Fig. 2, the thermal intensity impinging onto the receiver is $q_{\text {sun }}, q_{\text {absorbed }}$ being absorbed by the window and $q_{\text {reflected,glass }}$ being reflected; the remaining energy, $q_{3}$, impinges on the selective coating. Part of $q_{3}$ goes through the pipe to the heat working fluid, while the other part is transferred to the air and environment through processes of reflection, conduction, convection and radiation.

The heat transfer coefficient from the inner surface of the tubes to the fluid, $h$, has been simulated by the correlation provided by Gnielinski [34], which gives the Nusselt number, $\mathrm{Nu}$, proven to have errors bellow 10\% [35]:

$$
\begin{aligned}
& N u=\frac{(f / 8)(\operatorname{Re}-1000) P r}{1+12.7(f / 8)^{1 / 2}\left(\operatorname{Pr}^{2 / 3}-1\right)} \\
& N u=\frac{h D}{k}
\end{aligned}
$$

where $R e$ is the Reynolds number, Pr the Prandtl number, $f$ the friction coefficient, given by Moody's correlation [35,36], and $k$ the thermal conductivity of the fluid.

Other heat transfer coefficients, such as the global coefficient for thermal losses, $U$,which characterizes thermal losses to the air by convection and depends on the wind, are obtained from the literature [37].

It is necessary to define the mass flow and the pressure drop for the hydraulic process characterization (Eq. (3)) . The former depends on the fluid velocity, the number of tubes and their inner diameter, while the latter depends on its velocity as well, on the friction factor and the hydraulic circuit dimensions, i.e. diameter and length:

$\dot{m}=n \cdot \rho \cdot \frac{\pi \cdot D_{i}^{2}}{4} \cdot v$

$\Delta P=f \frac{\rho v^{2}}{2 D_{i}} 2 L$

where the factor " 2 " is given by the fact that the fluid has to come back after passing through the receiver.

This model permits one to obtain the fluid outlet temperature, $T_{\text {out }}$, and thus the thermal or energy efficiency, $\eta_{t h}$, that is the ratio of power absorbed by the fluid to radiation power impinging on the receiver:

$\eta_{\text {th }}=\frac{\dot{Q}_{\text {gain }}}{\dot{Q}_{\text {sun }}}$

Nevertheless, the thermal efficiency is not enough to characterize the receiver performance; it is well known that high working fluid temperatures convey higher efficiencies in the thermodynamic cycle at the power block, with the obvious limit of Carnot efficiency. In addition, pumping power, $\dot{W}_{p}$, must be taken into 
account because it may imply important parasitic power losses, depending on the heat carrier fluid used. For these reasons, the exergetic efficiency, $\eta_{\text {ex }}$, is defined $[3,12]$ :

$\eta_{e x}=\frac{\dot{Q}_{\text {gain }} \cdot\left(1-\frac{T_{\text {air }}}{T_{\text {out }}}\right)-\dot{W}_{p}}{\dot{Q}_{\text {sun }} \cdot\left(1-\frac{T_{\text {air }}}{T_{\text {sun }}}\right)}$

The outputs of the program, $T_{\text {out }}, \eta_{t h}$ and $\eta_{\text {ex }}$, depend on several variables:

- Inlet temperature, $T_{\text {in }}$ : The reference is taken as $290^{\circ} \mathrm{C}$, as it is the case for Andasol power plant. This is due to the need of transferring heat to molten salts, which solidify at $254^{\circ} \mathrm{C}$ [38], to store it. However, some solar power plant do not have thermal storage, and so inlet temperature could be lower; thus for some simulations it has been fixed to $200^{\circ} \mathrm{C}$.

- Thermal flux onto receiver, $q_{\text {sun }}$ : It depends on the concentration achieved by the solar field, the mirrors reflectivity, and the Direct Normal Irradiation (DNI).

- Receiver length, $L$ : When comparing different thermal fluxes onto the receiver, it will vary so that the total power impinging on the receiver is equal for all simulations.

- Receiver width, $W$ : It may be admitted as the distance from the furthest mirror to the receiver times the inherent aperture of the reflected radiation, which is always larger than $9 \mathrm{mrad}-$ sun's natural light aperture. As this depends on the solar field design, and the present work is focused on the receiver, $W$ has been fixed to $0.49 \mathrm{~m}$ for all simulations.

- Tubes external and internal diameters, $D_{e}$ and $D_{i}$ : They determine the heat transfer and fluid mechanics processes. The ratio $D_{e} / D_{i}$ is fixed to 1.167 as a first approximation to give the same mechanical strength to all configurations [39]. The number of tubes seen in Fig. 1 is established by the receiver width and the external diameter, so that all the tubes occupy the whole receiver area, see Eq. (9) and Table 1.

- Fluid: For this study Therminol VP1 is considered, although the LFR system could also work with Direct Steam Generation or with molten salts.

- Fluid velocity, $v$ : It has a great effect on the pumping power and Reynolds number (and thus on the heat transfer coefficient). If the fluid output temperature is fixed, the fluid speed becomes a result of the program.

- Optical and thermal parameters: Such as selective coating absorptivity, glass reflectivity, and pipe thermal conductivity. They are taken from the literature.

- Air and ground temperatures: They are fixed during all simulations, with values in agreement with the purpose of this study.

$$
W=n \cdot D_{e} \propto n \cdot D_{i}
$$

Table 1

External $D_{e}$ and internal $D_{i}$ diameters of each pipe depending on the number of tubes, $n$, for a $49 \mathrm{~cm}$ wide receiver.

\begin{tabular}{lcc}
\hline$n(-)$ & $D_{e}(\mathrm{~cm})$ & $D_{i}(\mathrm{~cm})$ \\
\hline 3 & 16.3 & 14.0 \\
5 & 9.8 & 8.4 \\
7 & 7.0 & 6.0 \\
9 & 5.4 & 4.7 \\
11 & 4.5 & 3.8 \\
19 & 2.2 & 2.6 \\
25 & 2.0 & 1.7 \\
31 & 1.6 & 1.4 \\
33 & 1.5 & 1.3 \\
35 & 1.4 & 1.2 \\
\hline
\end{tabular}

From these variables one can obtain other parameters such as the Reynolds number, $R e$, the heat transfer coefficient, $h$, and the thermal transfer surface, as well as the results of the simulation, i.e. pumping power, $\dot{W}_{p}$, gained heat, $\dot{Q}_{\text {gain }}$, exit temperature, $T_{\text {out }}$, and thermal and exergetic efficiencies, $\eta$ th and $\eta_{\text {ex }}$.

\section{Results: Fresnel receiver optimization}

It has been seen in previous section that there are many design variables of the receiver; however, this study pays special attention to how the exergetic efficiency is affected by the most relevant design variables, namely the tubes diameter and the fluid speed, for different radiation intensities (directly linked to the solar concentration ratio). Inlet temperatures is another data representing working conditions of the plant, and its effect is also studied.

The tubes diameter is a design parameter that will be fixed once the power plant is designed, while the fluid speed is an operation parameter that may be changed along the day and the year in order to obtain the desired outlet conditions. The inlet temperature could be considered as an operation parameter as well; however, there must be a design inlet temperature for the design of the heat exchanger or boiler, which works best in stationary and constant conditions.

The radiation intensity is obviously imposed by the climate and the season of the year, as well as by the optic performance of the solar field, i.e. the concentration factor. It should be pointed out that the radiation flux impinging on a receiver surface from a Fresnel mirror array is far from uniform, as all mirrors are normally focused onto the central line of the receiver in order to achieve high radiation concentrations. This fact may be observed in Fig. 3, where the average radiation flux across a $50 \mathrm{~cm}$ wide receiver, and along the day 21st June, is depicted, admitting the light natural aperture semi-angle to be $4.65 \mathrm{mrad}$, and the mirrors surface error semi-angle $10 \mathrm{mrad}$ [40]. This corresponds to calculations carried out with

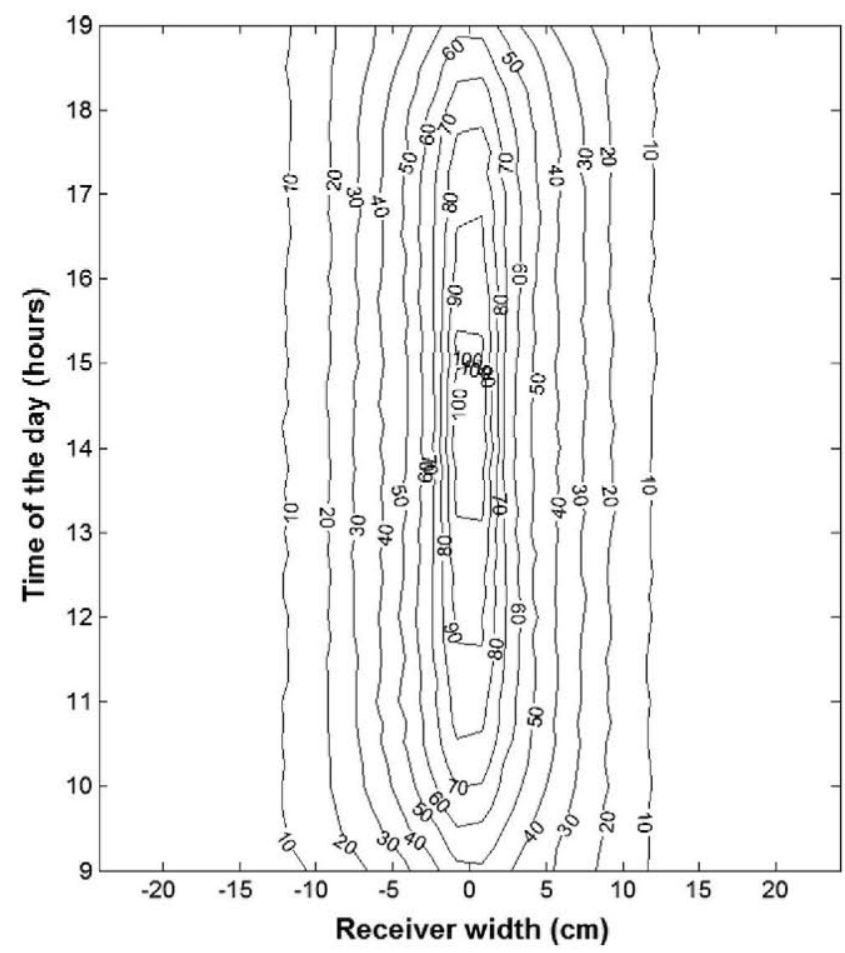

Fig. 3. Radiation intensity $\left(\mathrm{kW} / \mathrm{m}^{2}\right)$ variation across the Fresdemo receiver width, along the day 21st June, taking into account a natural solar aperture semi-angle of $4.65 \mathrm{mrad}$ and surface error of $10 \mathrm{mrad}$, and admitting DNI of $850 \mathrm{~W} / \mathrm{m}^{2}$, from [40]. 
the construction data of the Fresdemo prototype at Planta Solar de Almerfa (PSA).

One can observe that the distribution varies along the day, and it would be different for any other day of the year. This is due to the influence of the light natural aperture and mirrors surface and tracking errors together with the variation of the distance traveled by a reflected ray along the day and year, and the impossibility to focus a fixed point or line when the light source position changes. Therefore, a complete characterization of thermal process, including not only different average fluxes, but also their distributions, as well as different operation conditions, would be difficult to deal with. For this reason, the present study, which aims to characterize the basic physics of linear thermal receivers, assumes a uniform radiation flux impinging onto the receiver.

One should take into account that heat transfer from the selective coating of one tube to the heat carrier fluid depends mainly on the tube diameter and the flux impinging onto that tube, the effect of the radiation flux to other tubes of the receiver being of second order. Thus, it seems adequate to assume uniform radiation flux for the paper objectives.

In the following, some selected results are shown and commented, in order to highlight the features of the receiver thermal performance. First, the effect of varying the fluid speed is illustrated for a $300 \mathrm{~m}$ receiver with an impinging radiation of $8.33 \mathrm{~kW} / \mathrm{m}^{2}$ (i.e. a total thermal power of $1.225 \mathrm{MW}$ ), assuming a fluid inlet temperature of $290^{\circ} \mathrm{C}$. This radiation level can be considered as the lower limit in our design window. Values bellow it are not suitable to generate an appropriate thermal regime in the receiver, with an acceptable efficiency of the captured energy by the heat transfer fluid [12]. One can observe in Fig. 3 that this value only appears at the sides of the receiver for the day considered.

Fig. 4 shows the outlet temperature obtained for different tubes diameters as the fluid speed changes. Obviously for a given geometry, i.e. for a given $D_{e}$, as the fluid speed increases the outlet temperature diminishes, while an increase of the number of tubes (and thus a reduction of the cross section) implies an outlet temperature augmentation for a given fluid speed.

Eqs. (2), (5) and (9) may be gathered as follows:

$\dot{Q}_{\text {gain }} \propto v \cdot D_{e} \cdot \Delta T$

This explains Fig. 4, assuming that the heat gained by the fluid does not change importantly compared to $v$ and $D_{e}$ variations. It results from this figure that the receiver performance may be shown as a function of the outlet temperature instead of the fluid speed, as will be done from now on.

For the foregoing conditions, the exergetic efficiency reaches a maximum for moderate outlet temperatures, around $300^{\circ} \mathrm{C}$ (see Fig. 5). It is worth pointing out that the maximum efficiency

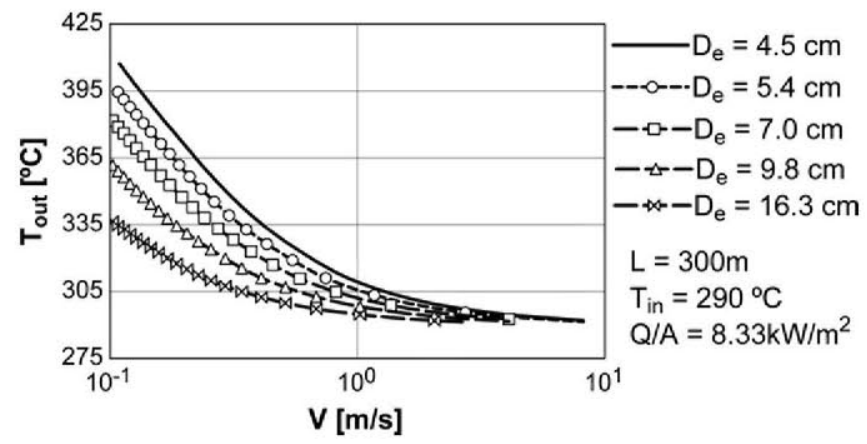

Fig. 4. Outlet temperature depending on the fluid speed for a $300 \mathrm{~m}$ receiver with $8.33 \mathrm{~kW} / \mathrm{m}^{2}$ impinging radiation when the inlet temperature is $290^{\circ} \mathrm{C}$ and for different tubes diameters.
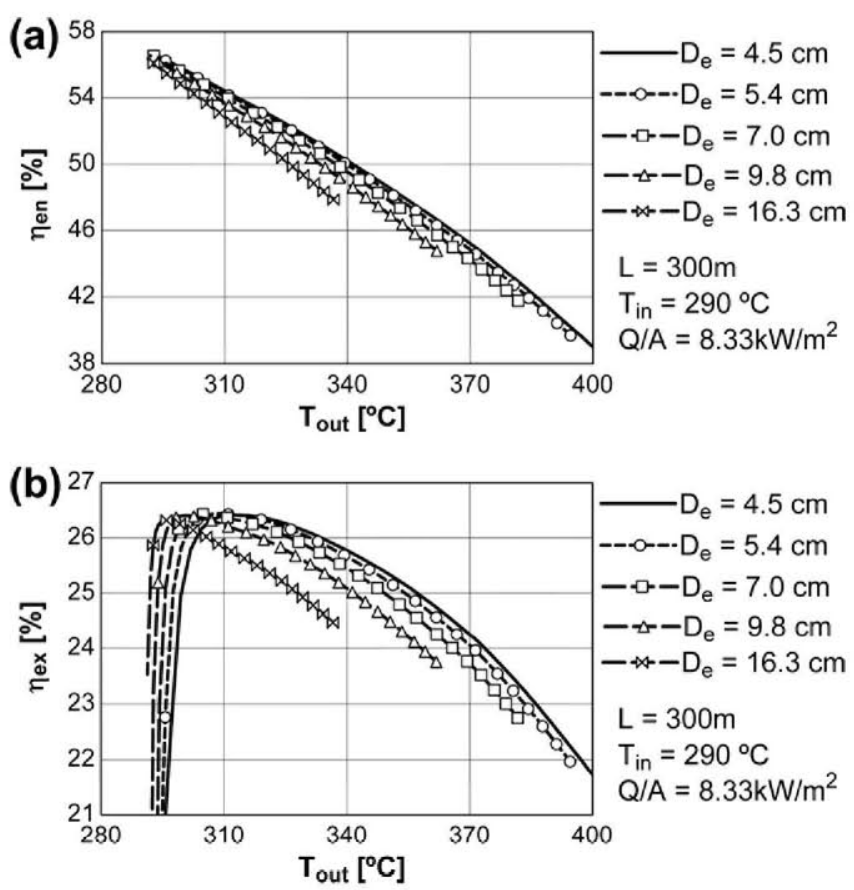

Fig. 5. (a) Thermal and (b) exergetic efficiencies depending on the fluid outlet temperature for a $300 \mathrm{~m}$ receiver with $8.33 \mathrm{~kW} / \mathrm{m}^{2}$ impinging radiation when the inlet temperature is $290^{\circ} \mathrm{C}$ and for different tubes diameters.

temperature increases as the tubes diameter gets smaller. It seems obvious from this figure that it is not worth increasing the fluid temperature to its maximum allowable, i.e. $400^{\circ} \mathrm{C}$, as the exergetic efficiency for such high temperatures is notably lower. This is due to the low radiation intensity, assumed to be $8.33 \mathrm{~kW} / \mathrm{m}^{2}$, i.e. a concentration ratio close to 10 suns for a DNI around $850 \mathrm{~W} / \mathrm{m}^{2}$. Such average concentration factor may be found in a Fresnel concentrator when the sun is far from its zenith. It was explained by Muñoz et al. [12] that the maximum exergetic efficiency temperature depends on the solar concentration, being lower for low solar radiations.

If the solar concentration is higher, for the same total thermal power impinging onto the receiver, the outlet temperature for which the maximum exergetic efficiency is achieved is notably higher, as shown in Fig. 6. For relatively high concentration ratios, around 30 suns, the influence of the receiver's tubes diameter becomes very important, the maximum exergetic efficiency changing from slightly more than $37 \%$ to nearly $40 \%$. It is remarkable as well that for diameters around $4.5 \mathrm{~cm}$, the maximum exergetic

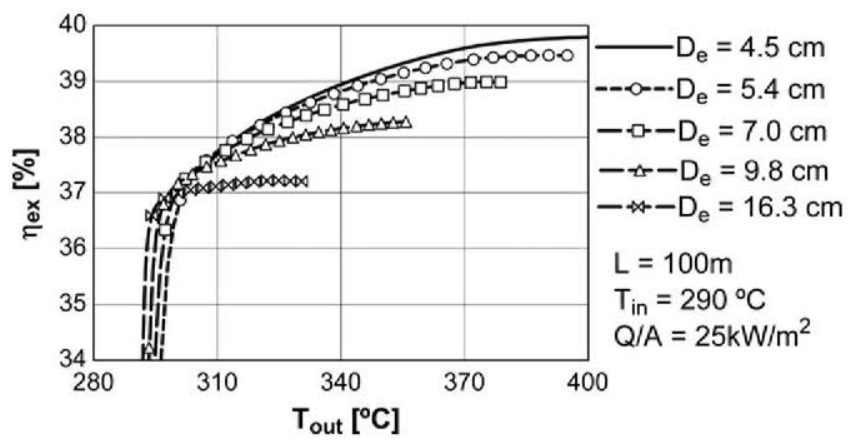

Fig. 6. Exergetic efficiency depending on the fluid outlet temperature for a $100 \mathrm{~m}$ receiver with $25 \mathrm{~kW} / \mathrm{m}^{2}$ impinging radiation when the inlet temperature is $290^{\circ} \mathrm{C}$ and for different tubes diameters. 


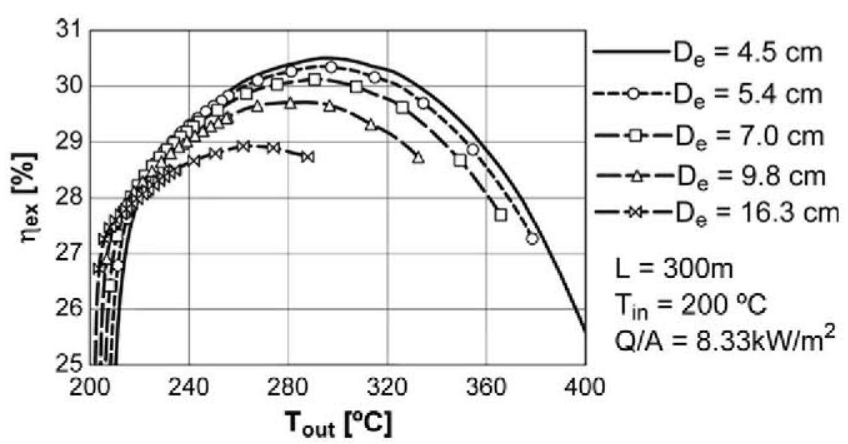

Fig. 7. Exergetic efficiency depending on the fluid outlet temperature for a $300 \mathrm{~m}$ receiver with $8.33 \mathrm{~kW} / \mathrm{m}^{2}$ impinging radiation when the inlet temperature is $200^{\circ} \mathrm{C}$ and for different tubes diameters.

efficiency is achieved at an outlet temperature of around $400^{\circ} \mathrm{C}$ (Therminol VP1 maximum temperature).

When comparing Figs. $5 \mathrm{~b}$ and 6 one can observe that the exergetic efficiency changes notably with the concentration ratio. This is an important matter regarding Fresnel collectors, as the average concentration may vary from 30 suns to 10 suns when the radiation source moves from its zenith towards the skyline.

In addition, it is worth analyzing the effect of the second variable defining the working conditions, namely the inlet temperature. One may observe in Fig. 7 that, for the same conditions assumed as for Fig. 5, but the inlet temperature being $90^{\circ} \mathrm{C}$ lower, the exergetic efficiency increases to almost $30 \%$ from less than $27 \%$.

From Figs. 5b and 7 one can deduce that the effect of the tubes diameter in the former is very limited because the inlet temperature is higher than the temperature of maximum exergetic efficiency corresponding to that flux, thus placing all maxima just above $290^{\circ} \mathrm{C}$. Decreasing the inlet temperature down to $200^{\circ} \mathrm{C}$ increases the exergetic efficiency by nearly $3.5 \%$ points, thus augmenting the power generation for the same receiver by more than $10 \%$.

However, decreasing the inlet temperature to $200{ }^{\circ} \mathrm{C}$ means that other storage system than molten salt may be required for Fresnel collectors, as they solidify at more than $250^{\circ} \mathrm{C}$. In fact, an option deserving some additional attention in this framework is the use of the same oil for storing the thermal energy if the required inlet temperature is low.

Figs. 6 and 7 show that the maximum exergetic efficiency increases as the tubes diameter diminishes. From this information

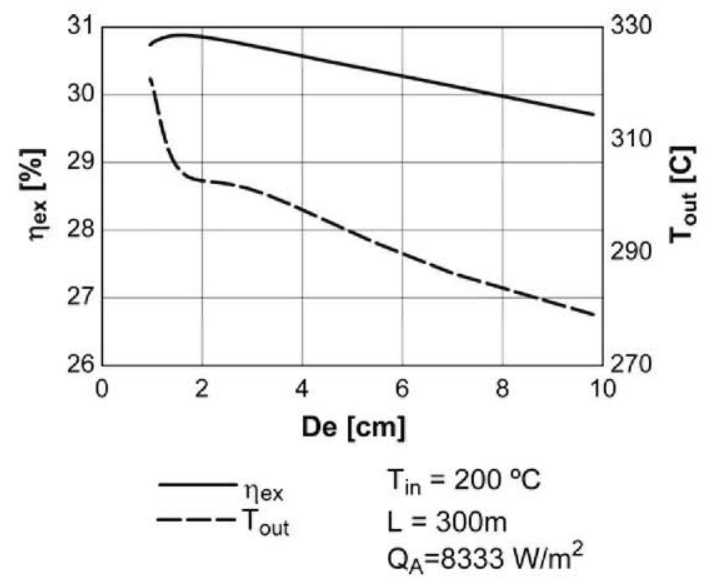

Fig. 8. Maximum exergetic efficiency and respective outlet temperature depending on the tubes diameter for a $300 \mathrm{~m}$ receiver with $8.33 \mathrm{~kW} / \mathrm{m}^{2}$ impinging radiation when the inlet temperature is $200^{\circ} \mathrm{C}$. it was obvious the need to analyze how the maximum exergetic efficiency varies with the tubes diameter, optimizing the outlet temperature, i.e. the fluid speed, for each case. This is first done for solar radiation intensity impinging onto the receiver of $8.33 \mathrm{~kW} / \mathrm{m}^{2}$, and an inlet temperature of $200^{\circ} \mathrm{C}$. Results are depicted in Fig. 8.

One can observe that the exergetic efficiency generally increases as the tubes get narrower, until a maximum is achieved at somewhere between $1 \mathrm{~cm}$ and $2 \mathrm{~cm}$. If tubes are even smaller, pumping power becomes non-negligible, and so the optimal mass flow decreases to reduce parasitic power, the outlet temperature increases, and thermal losses augment as well, the exergetic efficiency decreasing.

It is remarkable that the maximum exergetic efficiency diameters range coincides with the area where a sudden increase on the outlet temperature appears as the tubes get narrower. This is related to the diameter limit for pumping power: if tubes get narrower and the mass flow is maintained, the increase of pumping power becomes too important, and the exergetic efficiency decreases notably. As the program maximizes such efficiency, mass flow is reduced in order to limit pumping power, which implies an increase on the outlet temperature, maintaining the exergetic efficiency nearly constant. When tubes are too narrow, the outlet temperature and pumping power increase too much, resulting on an exergetic efficiency decrease.

If mass flow were constant, the fluid speed would be inversely proportional to the tubes diameter, and thus proportional to the number of tubes assuming a constant receiver width (see Eq. (5)). This trend is seen in Fig. 9 for wide tubes, i.e. for a small number of tubes. However, when tubes get narrower, the actual speed decreases compared to the lineal trend, which is linked with the foregoing process. Comparing Figs. 8 and 9, one can deduce that the outlet temperature increase for low number of tubes, i.e. wide tubes, is not mainly caused by a mass flow decrease, but to a more effective thermal process.

Variations on the fluid speed have a significant impact on pumping power as well. Reynolds numbers are well above 10,000 , and thus the flow may be considered as fully turbulent. This implies a friction factor that does not change importantly as Re increases [35]. From Eqs. (3), (5) and (6), it results:

$$
\begin{aligned}
& \Delta P \propto \frac{v^{2}}{D} \\
& \dot{W}_{p} \propto v^{3}
\end{aligned}
$$

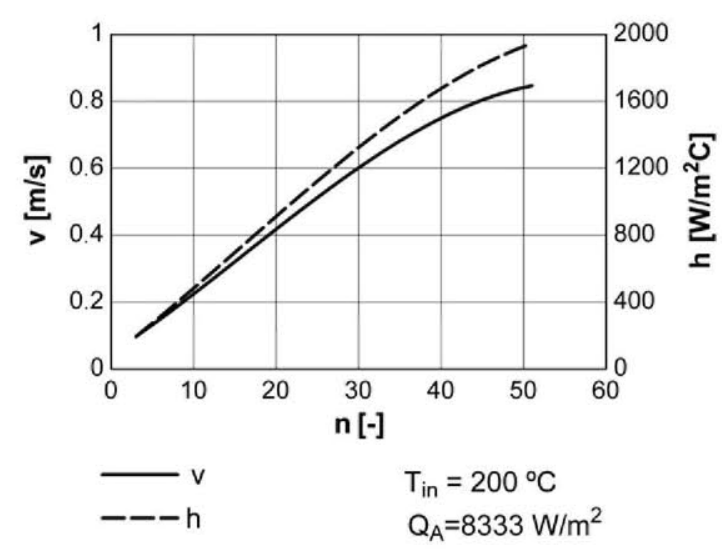

Fig. 9. Fluid speed for achieving the maximum exergetic efficiency and respective heat transfer coefficient obtained depending on the number of tubes (inversely proportional to their diameter) for a $300 \mathrm{~m}$ receiver with $8.33 \mathrm{~kW} / \mathrm{m}^{2}$ impinging radiation when the inlet temperature is $200^{\circ} \mathrm{C}$. 
This cubic trend is seen in Fig. 10, where the $x$ axis represents again the number of tubes, inversely proportional the tubes diameter after the assumptions made in Section 2. One can observe as well in this figure that the thermal power gained by the fluid gets lower as the number of tubes increases, and so does the thermal efficiency. This is due to the higher temperatures at the receiver surface caused by the smaller mass flow, which increases thermal losses, but increases the thermodynamic cycle efficiency.

Fig. 10 also shows the value of $\dot{Q}_{\text {gain }}-\dot{W}_{p} / \eta_{\text {th }-\mathrm{e}}$ for each $n$, where $\eta_{\text {th-e }}$ corresponds to the thermal to electric conversion coefficient. These values are somehow lower than $\dot{Q}_{\text {gain }}$, especially for high number of tubes due to the important increase of pumping power in this region. This is the reason for the exergetic efficiency diminution for numbers of tubes higher than 30 , i.e. tubes diameters smaller than $1.5 \mathrm{~cm}$.

From the foregoing figures one can deduce that there is a small range of tubes diameters that drive to a maximum exergetic efficiency, from $0.8 \mathrm{~cm}$ to $3 \mathrm{~cm}$ approximately. In this range, the outlet temperature is also limited to $300-310^{\circ} \mathrm{C}$, and so the thermal efficiency does not vary importantly neither. If tubes become larger than that - and so there are more tubes for the same receiver width-, the heat transfer coefficient $h$ diminishes (see Fig. 9), and so the thermal process is less effective, the optimal outlet temperature being lower. On the other hand, if chosen tubes are narrower, the hydraulic process requires too much pumping power, and thus the optimal mass flow decreases, the outlet temperature augments, and the overall process efficiency gets worse.

The same calculation has been carried out for a $150 \mathrm{~m}$ receiver with a radiation intensity of $16.66 \mathrm{~kW} / \mathrm{m}^{2}$, i.e. the same total power impinging onto the receiver as in the former case. Some of the results are represented in Fig. 11. Recall that the maximum temperature that the oil admits is around $400^{\circ} \mathrm{C}$, but this limit has not been obeyed in this theoretical simulation in order to point out the features of the physics underlying in these cases.

One can observe in Fig. 11 that for this case, where the radiation intensity is twice as large as in the previous case (with the same total power impinging onto the receiver, $1.125 \mathrm{MW}$ ), exergy efficiencies are $9 \%$ points higher. This is achieved for slightly narrower tubes, which is due to the smaller length of the receiver that reduces the pumping power required.

The same trend is observed in Fig. 11 as was in Fig. 8, with a narrow diameters range where the exergetic efficiency is maximized. If diameters become larger, the heat transfer process is less effective, while if they become narrower, pumping power is too important. The temperature at which the maximum efficiency is

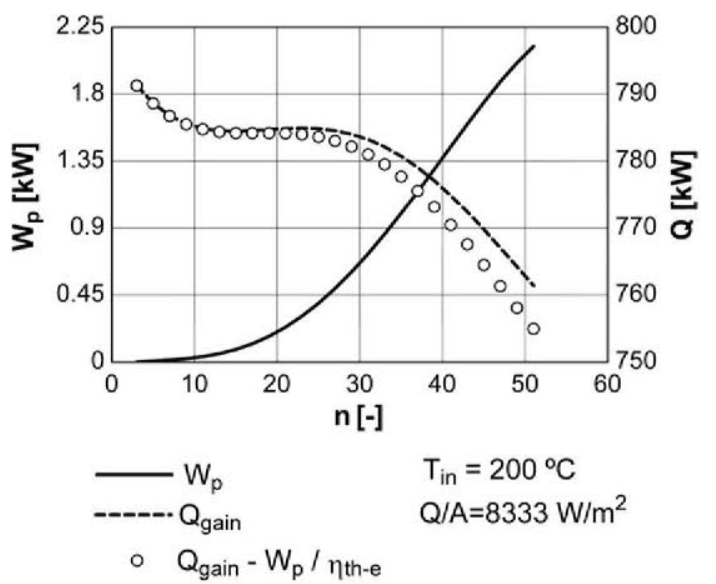

Fig. 10. Pumping power required and heat gained by the fluid depending on the number of tubes (inversely proportional to their diameter) for a $300 \mathrm{~m}$ receiver with $8.33 \mathrm{~kW} / \mathrm{m}^{2}$ impinging radiation when the inlet temperature is $200^{\circ} \mathrm{C}$

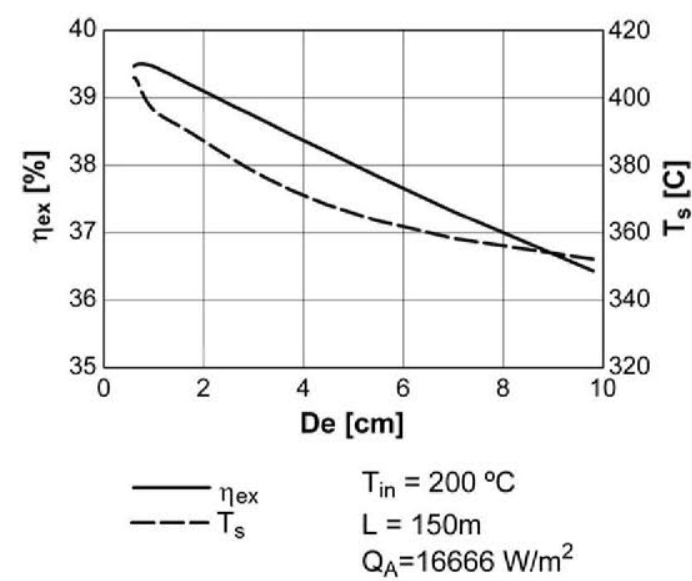

Fig. 11. Maximum exergetic efficiency and respective outlet temperature depending on the tubes for a $150 \mathrm{~m}$ receiver with $16.66 \mathrm{~kW} / \mathrm{m}^{2}$ impinging radiation when the inlet temperature is $200^{\circ} \mathrm{C}$.

achieved is now around $400^{\circ} \mathrm{C}$, notably higher than for the former case. This is due to the fact that the optimal outlet temperature for a lineal receiver depends on its concentration ratio [12].

The difference of optimal outlet temperature observed when compared to the $16.6 \mathrm{~kW} / \mathrm{m}^{2}$ case, implies that the fluid temperature increase along the receiver is double for $25 \mathrm{~kW} / \mathrm{m}^{2}$. On the contrary, the gained thermal power increases just by $11 \%$ approximately ( $0.87 \mathrm{MW}$ vs $0.78 \mathrm{MW}$ ). As a consequence, the mass flow must be smaller (see Eq. (2)), which reduces at the same time pumping power, and makes the optimum tubes diameters smaller. However, there is not an important efficiency difference between diameters of $0.7 \mathrm{~cm}$ and $1.5 \mathrm{~cm}$, and so one could look at reducing the power plant investment by using the cheapest tubes within a

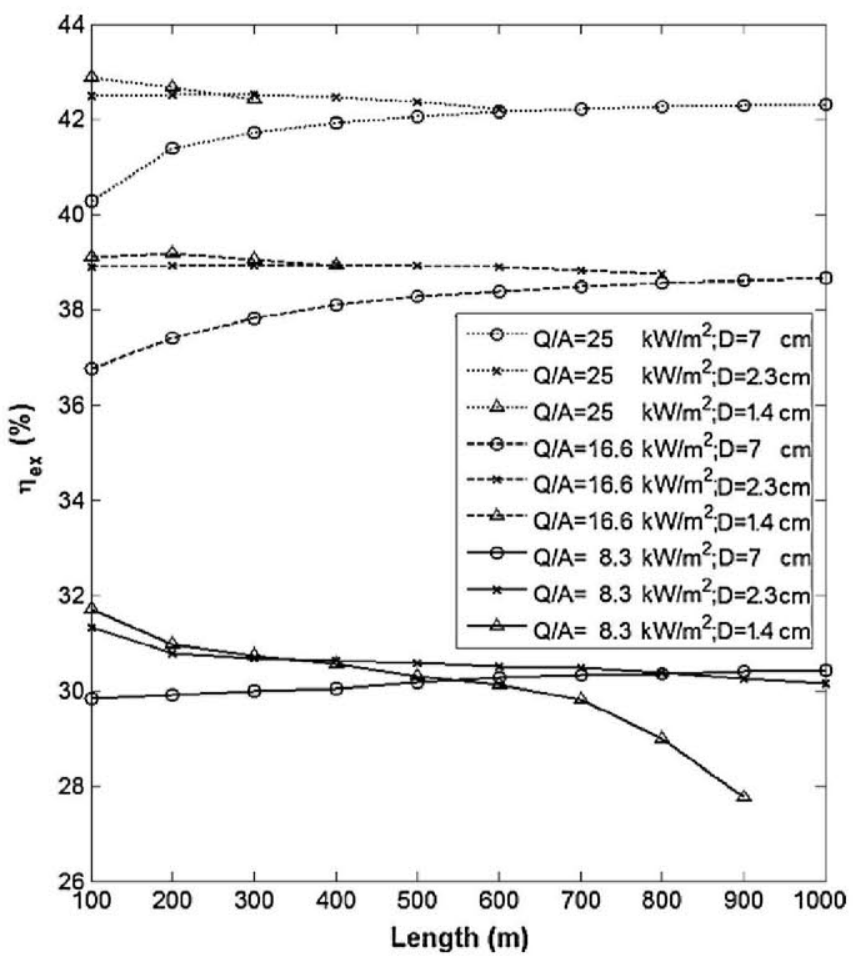

Fig. 12. Exergetic efficiency produced in a $0.49 \mathrm{~m}$ wide Fresnel receiver depending on the impinging radiation intensity and the receiver length, the inlet temperature being $200^{\circ} \mathrm{C}$. 
wide range of diameters, taking into account invest and maintenance costs: material used, tubes fouling, etc.

Finally, a numerical simulation has been carried out to obtain the optimal receiver length, depending on the radiation intensity impinging onto it and on the tubes diameter, which is depicted in Fig. 12. This has been done taking into account that the maximum temperature of the oil Therminol VP-1 is around $392^{\circ} \mathrm{C}$, i.e. the fluid speed is optimized to maximize the exergetic efficiency, and if this gives an outlet temperature larger than its allowed maximum, then it is fixed to $392^{\circ} \mathrm{C}$, obtaining the fluid speed from this constraint. When the pressure drop is above 10 bar the point is not drawn, as this would drive to unsafe conditions in relation to oil boiling.

One can observe in Fig. 12 that larger radiation intensities convey to better efficiencies, as previously stated; nevertheless, the effect of increasing from $8.3 \mathrm{~kW} / \mathrm{m}^{2}$ to $16.6 \mathrm{~kW} / \mathrm{m}^{2}$ is notably more important than from the latter to $25 \mathrm{~kW} / \mathrm{m}^{2}$. This is coherent with the results formerly given, as well as with those given by Muñoz et al. [12], taking into account that the outlet temperature is limited.

Fig. 13 shows the outlet temperature for the previous simulation, which is an important information for a proper analysis of the efficiency obtained. None of the optimized temperatures for an intensity of $8.3 \mathrm{~kW} / \mathrm{m}^{2}$ reaches the maximum permitted, $392^{\circ}$. When the receiver's tubes diameter is $1.4 \mathrm{~cm}$, the temperature is close to its maximum $(900 \mathrm{~m})$; however, the pressure drop is too high, in fact higher than 10 bar for a $1000 \mathrm{~m}$ receiver. For higher radiation intensities, the maximum temperature is virtually always reached, and thus a proper optimization is not carried out; the results are then simply the solution to the simulation imposing an outlet temperature of $392^{\circ} \mathrm{C}$. Due to this constrain, the average fluid temperature is the same for these cases.

Fig. 14 shows the thermal efficiency obtained in the foregoing simulations. One can observe, when comparing it to Fig. 13, that

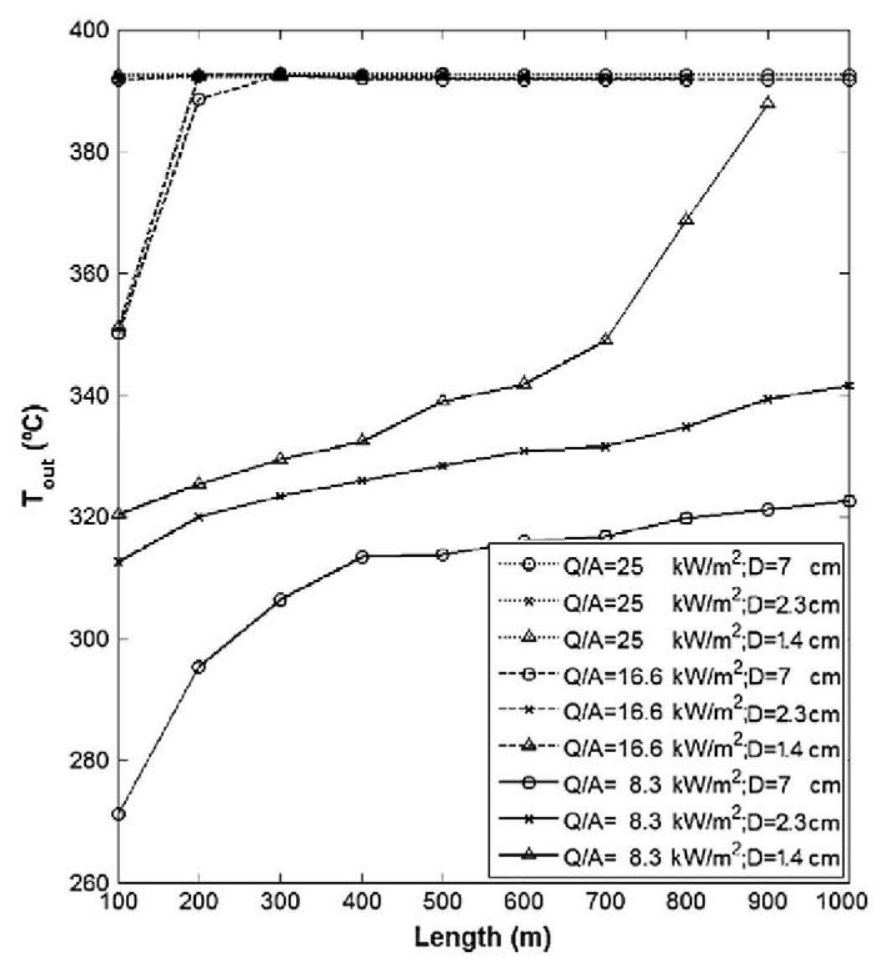

Fig. 13. Outlet temperature for obtaining the maximum exergetic efficiency depending on the impinging radiation intensity and the receiver length, the inlet temperature being $200^{\circ} \mathrm{C}$. when the outlet temperature is limited to its maximum, $392^{\circ} \mathrm{C}$, the thermal efficiency increases as the length does due to the higher fluid mass flow and thus, the higher heat transfer coefficient. However, this has a saturation shape, and the thermal efficiency improvement is lower as the length increases. On the contrary, when the outlet temperature is not fixed to its maximum, thermal efficiency is inversely proportional to $T_{\text {out }}$, as higher temperatures - obtained thanks to the higher total thermal power impinging onto the receiver - increase thermal losses.

Figs. 12-14 give a global view of the plant optimization process, and the physics beneath. A decrease in exergetic efficiency is always observed for long receivers when the tubes are too narrow; recall that the receiver cross section is proportional to the tubes diameter, and thus the fluid speed is proportional to the inverse of such diameter for a given mass flow. As a result, very narrow tubes imply an increase on pumping power that becomes of the order of magnitude of the thermal power, and the exergetic efficiency decreases as the receiver becomes longer. On the other hand, when tubes are wide and/or when the receiver is short, pumping power has an influence of second order on the process. When this happens, an increase on the receiver length implies either an increase on the thermal efficiency due to the increase of the fluid speed when its outlet temperature is already the maximum allowable, or an increase on the outlet temperature thanks to a higher power impinging onto the receiver. As a result, there is an exergetic efficiency increase.

Fig. 12 has a great importance for the development of linear Fresnel reflectors. It shows that even though the exergetic efficiency may vary importantly along the day, from $32 \%$ to $42 \%$ approximately, all maximum values for each radiation intensity are given for the same design of the receiver: $100 \mathrm{~m}$ length and tubes diameter of $1.4 \mathrm{~cm}$. This implies that the same design is optimal for all operating conditions, and thus it is not necessary to find a compromise between noon and other time of the day, or summer and winter.

In addition, it is remarkable that the efficiency obtained is not very different for $2.3 \mathrm{~cm}$ tubes, while for $7 \mathrm{~cm}$ the behavior gets worse. Therefore, the design for a good performance is flexible within a given range, and the final design can be fixed with detailed economic considerations. That is to say, technical uncertainties are not a design risk thanks to the robustness of the thermal behavior within some limits, i.e. $1-2.5 \mathrm{~cm}$.

Finally, it is worth noting that a solar power plant will be built by collector modules, and the optimization analysis carried out here is aimed at determining the module length giving the best performance. From Fig. 12 one can deduce that it is better to have three modules $300 \mathrm{~m}$ long than a unique module of $900 \mathrm{~m}$ if the receiver's tubes diameter is in the appropriate range (around $1.4 \mathrm{~cm}$ ), and for any radiation intensity within the range considered.

\section{Discussion on the computational results. The physics of linear thermal receivers}

The results observed in the previous section may be explained by easy-to-follow physical models. This is important when complex programing simulations are carried out, as it enables one to find out possible errors and to understand the process, making possible to improve future designs.

Two main processes must be kept in mind: on the one hand, the thermal process is governed by the heat transfer balance Eq. (1) - and the thermal energy balance - Eq. (2). On the other hand, the fluid mechanics process is governed by the hydromechanical balance, expressed as the equality between the pressure drop along the circuit and the pressure boost given by the pump Eq. (3). 


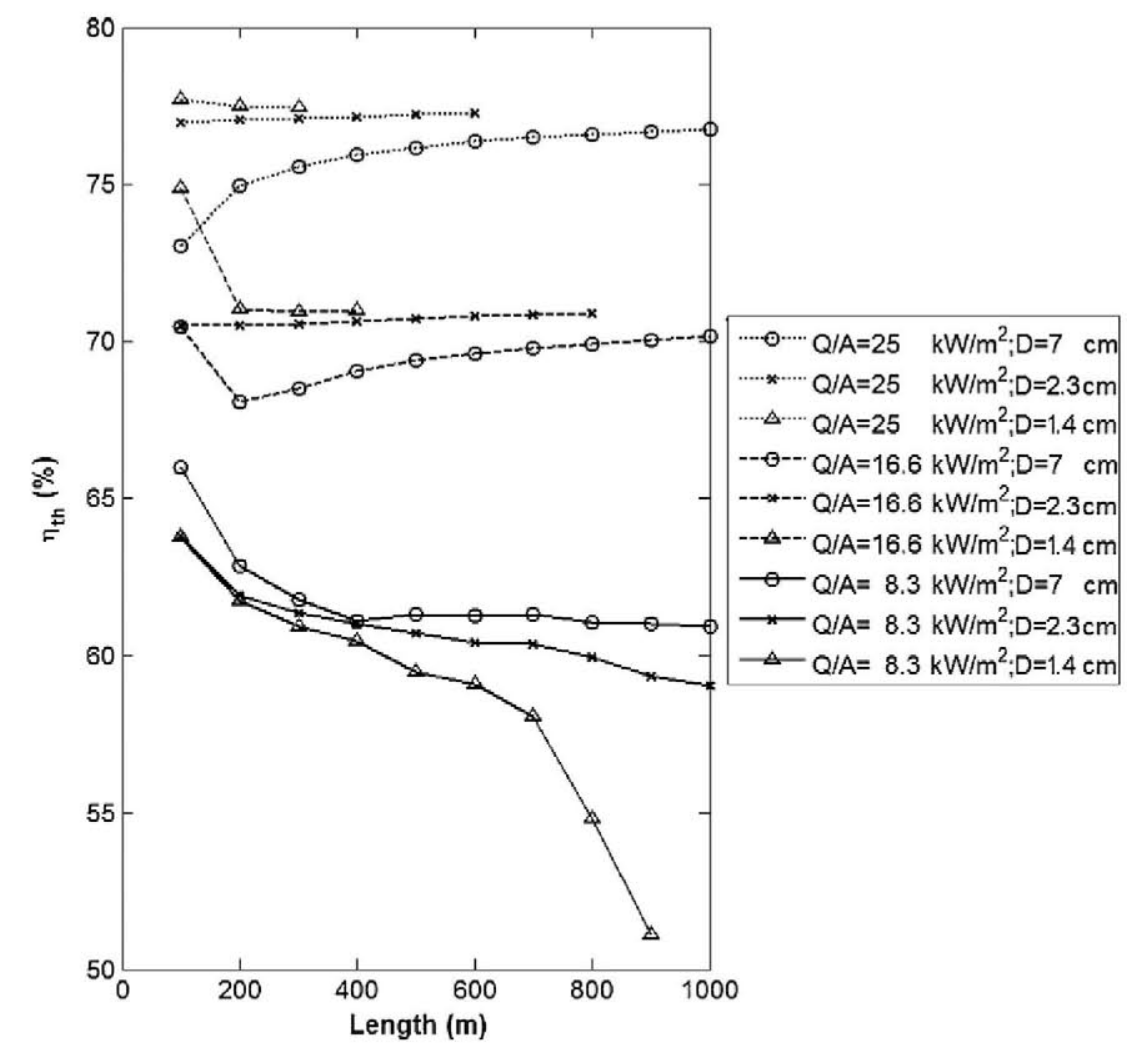

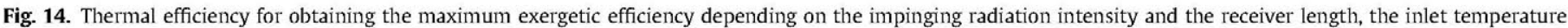
being $200^{\circ} \mathrm{C}$.

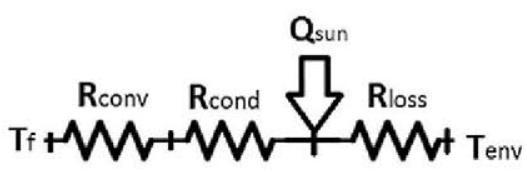

Fig. 15. Equivalent thermal circuit for the heat transfer process that takes place in a linear receiver.

The heat transfer process might be studied by an equivalent thermal circuit with heat generation at the external surface of the tubes, i.e. at the selective coating, as depicted in Fig. 15. Heat might flow from there either to the environment, which is at a given temperature $T_{\text {air }}$, or to the fluid, at $T_{f}$. The thermal resistance to the environment, $R_{\text {loss }}$, is the inverse of the global coefficient for thermal losses to the environment, $U$. Therefore, the heat transferred to the environment mainly depends on the surface temperature.

In the opposite thermal branch, there are two main thermal resistances in series from the external surface to the fluid: the conduction through the tube wall, and the convection from the inner surface to the fluid itself. The former has the following definition for cylindrical tubes:

$R_{\text {cond }}=\frac{\log \left(D_{e} / D_{i}\right)}{2 \pi L k}$

where log refers to natural logarithm. Therefore, it is constant for any diameters as $D_{e} / D_{i}$ is constant - see Section 2 . It results that the only thermal resistance that has an important variation with the receiver design is the internal convection resistance, that depends on the convection heat transfer coefficient, $h$, as follows:

$R_{\text {conv }}=\frac{1}{n \pi L D_{i} h} \propto \frac{1}{h}$
With this easy-to-follow analysis one can observe that, for a given fluid temperature, increasing the heat transfer coefficient reduces the thermal resistance from the outer surface of the tube to the fluid, thus reducing the former's temperature and so the thermal losses to the environment. Nevertheless, this effect is limited by the conduction resistance: when $R_{\text {conv }}$ becomes very small compared to $R_{\text {cond }}$, it is not advisable to still increase $h$ if this implies an increase on pumping power, as this would have a negligible effect on the thermal process.

Design choices, namely the tubes diameter and the mass flow, have a thermal effect, making the heat transfer coefficient vary. This has been simulated by the correlation provided by Gnielinski [34], previously stated in Eq. (4), which gives the Nusselt number approximation with errors bellow $10 \%$ [35].

Additionally, the friction factor, $f$, was simulated by Moody's correlation, which depends on the relative roughness and on the Reynolds number. Therefore all physical phenomena depend on dimensionless numbers, $R e$ and $P r$, and on the tubes diameter, $D$, if other parameters such as the absolute roughness are fixed.

The average fluid temperature has limited influence on the dimensionless numbers, and thus on both the fluid dynamics and thermal processes, as seen in Fig. 16. One can observe that, for the temperatures range considered, the effect of this parameter is lower than $20 \%$ for the heat transfer coefficient and $10 \%$ for the friction coefficient. This is not actually important, especially taking into account that the values given by the equations used may have errors up to $10 \%$. In addition, the average temperature range is half of the temperatures considered in this graph, and thus its effect may be considered of second order.

However, the fluid temperature has a great effect on the overall process. On the one hand, high outlet temperatures imply high Carnot coefficients, $C_{f}$, and thus better exergetic efficiencies. This is given by the relation $1-T_{\text {air }} / T_{\text {out }}$, being its derivate 


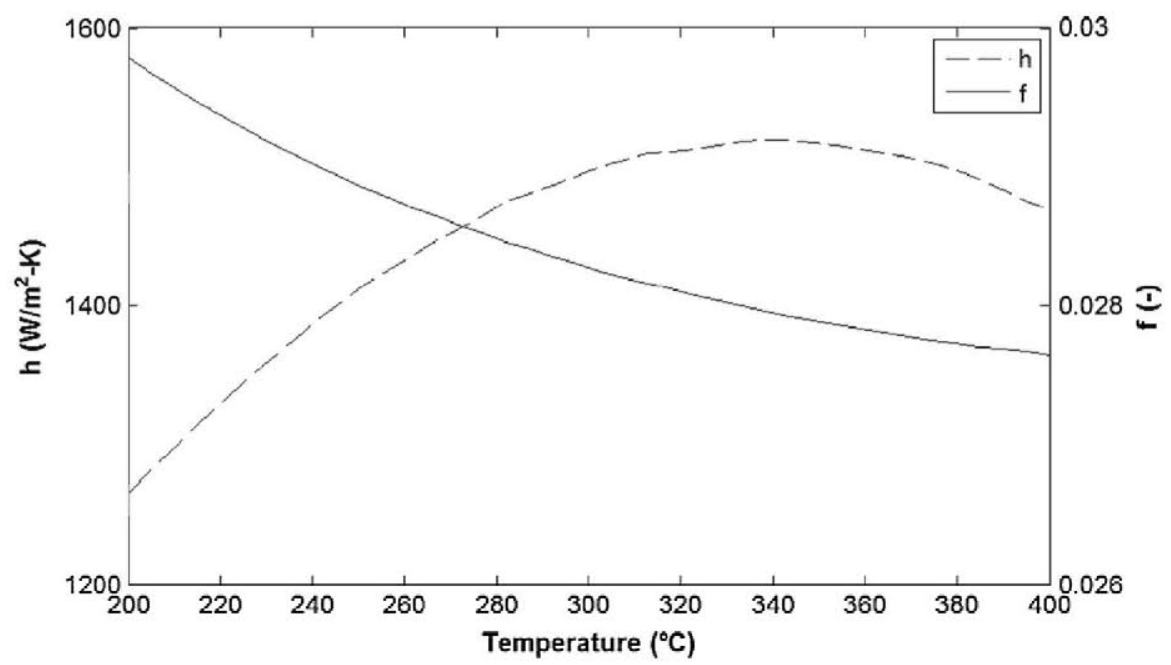

Fig. 16. Heat transfer coefficient and friction coefficient variation depending on the temperature for a $2.3 \mathrm{~cm}$ tubes receiver and $0.5 \mathrm{~m} / \mathrm{s}$ flow speed.

$\partial C_{f} / \partial T_{\text {out }}=T_{\text {air }} / T_{\text {out }}^{2}$. Therefore the effect on the exergetic efficiency of increasing the outlet temperature becomes less important for high temperatures.

On the other hand, high fluid temperatures imply high tube surface temperatures as well, and thus high thermal losses. This process is governed by conduction, convection and radiation and thus cannot be easily expressed. However, it is obvious that thermal losses increase as the receiver temperature raises up with a trend with linear and fourth order exponential components, and therefore, the effect of increasing the temperature becomes more important.

Recall that thermal losses depend on the receiver geometry, on the materials used and on its temperature, but it does not depend directly on the impinging radiation. As a result, for a given receiver at a given temperature, if the radiation intensity is higher, the heat flow to the fluid becomes higher, the thermal efficiency being higher as well. This explains that the maximum exergetic efficiency temperature is higher as the intensity increases (see Figs. 5, 6 and 12).

Regarding the Reynolds number, it depends on the fluid speed and on the tubes diameter. Considering Eqs. (5) and (9) it results that, for a given temperature $T_{f}$, Reynolds is proportional to the mass flow, as both are proportional to $v \cdot D$. These parameters, $D$

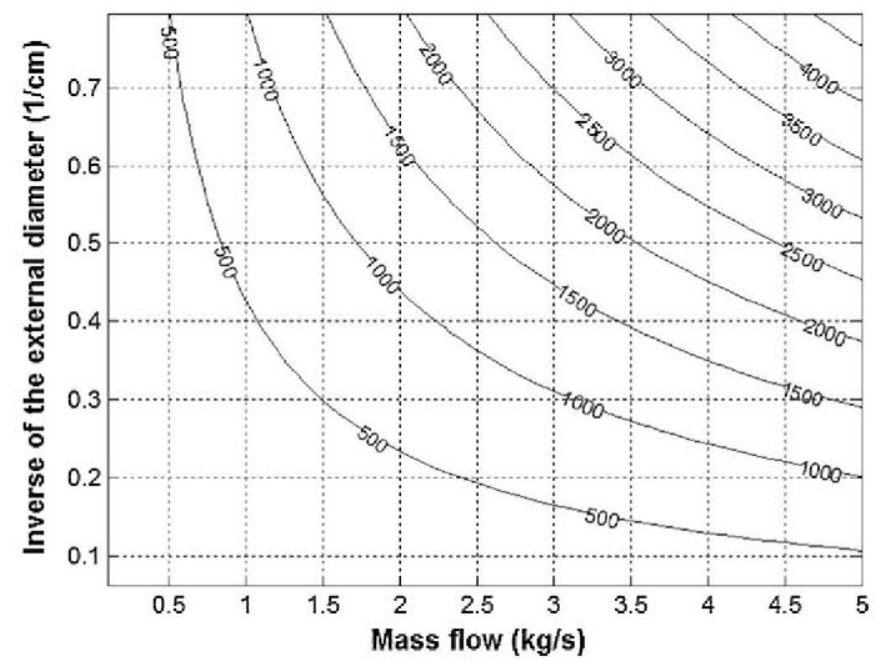

Fig. 17. Heat transfer coefficient $\left(\mathrm{W} / \mathrm{m}^{2}\right)$ depending on the tubes diameter and on the mass flow for an average fluid temperature of $300^{\circ} \mathrm{C}$. and $R e$, have an important effect on the heat transfer coefficient and on the pumping power, which may be expressed by scaling laws.

It must be noted that, assuming $\mathrm{Pr}$ and $f$ constant, $\mathrm{Nu}$ is proportional to Re, see Eq. (4). In addition, the heat transfer coefficient is directly proportional to $\mathrm{Nu}$, and inversely to $\mathrm{D}$. Therefore, it holds:

$h \propto \frac{\dot{m}}{D}$

It was seen in Fig. 9 that, the mass flow not varying notably, i.e. Re approximately constant, $h$ increases proportionally to $1 / D$. In Fig. 17 the heat transfer coefficient is depicted as a function of the inverse of tubes diameter ( $y$ axis) and the mass flow ( $x$ axis). One can observe that the distance between two following level curves is constant for a given $\dot{m}$ as the fraction 1/D increases, and for a given $D$ as $\dot{m}$ varies, which is in agreement with Eq. (15). Remark that the heat transfer coefficient variation with the tubes diameter and the mass flow is notably larger than with the average fluid temperature, as seen when comparing Figs. 16 and 17.

In the study of the flow dynamics process, it is deduced from Fig. 16 that the fluid temperature does not induce significant changes in pumping requirements. This is not the case of the tubes diameter and the mass flow. It was said in Section 3 that pumping

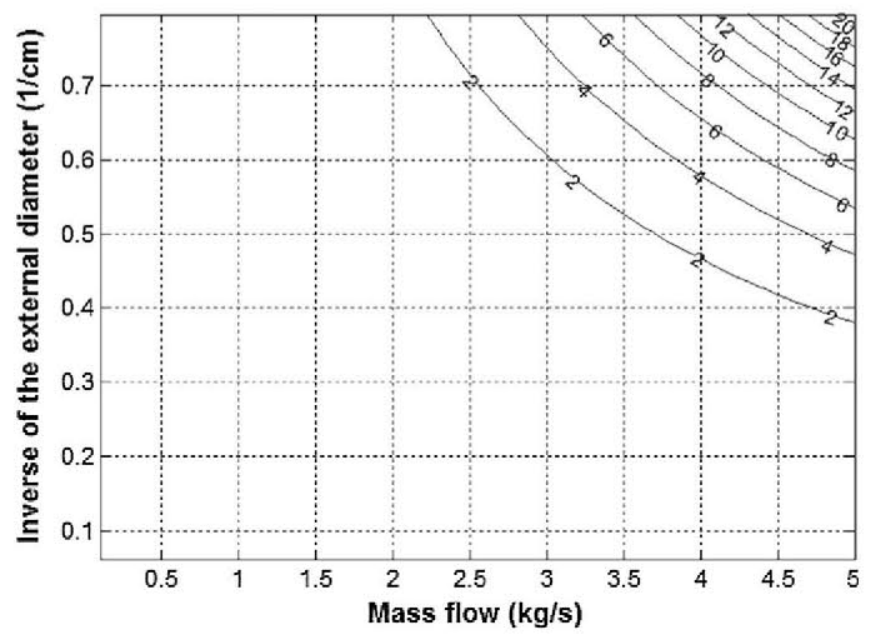

Fig. 18. Pumping power per unit length $(\mathrm{W} / \mathrm{m})$ depending on the tubes diameter and on the mass flow for an average fluid temperature of $300^{\circ} \mathrm{C}$. 
power is proportional to $v^{3}$ and thus, from Eqs. (5) and (9), to $\dot{m}^{3}$ and $D^{-3}$.

$\dot{W}_{p} \propto \dot{m}^{3} \cdot\left(\frac{1}{D}\right)^{3}$

This double cubic relation is seen in Fig. 18, where the pumping power does not vary for low $1 / D$ and $\dot{m}$, but increases rapidly for large values.

A simplified way to present the problem to be optimized is as follows: a given mass flow $\dot{m}$ of the heat carrier fluid, with a specific heat $c_{p}$, must enter the collector, with a given impinging thermal flux, at temperature $T_{i n}$, and exit it at $T_{\text {out }}$, i.e. it must gain a thermal power $\dot{Q}_{\text {gain }}$. A thermal optimization process would consist in finding the shortest collector to get this heating, i.e. the number of tubes producing the highest linear thermal power density across the tubes toward the heat carrier fluid, from the heat source generated by the radiation absorption in the selective coating.

It has been seen that $R e \propto \dot{m}$, and so it would be constant for this simulation. Thus, from Eq. (15), $h \propto 1 / D$. Assuming the thermal circuit seen in Fig. 15, and taking into account Eqs. (13) and (14) it holds that the global coefficient for heat transfer to the fluid is:

$U_{f}=\frac{1}{R_{\text {cond }}+R_{\text {conv }}}=\frac{1}{a \cdot D+b}$

where $a$ and $b$ are two constants. Therefore, decreasing the tubes diameter always means increasing the global coefficient for heat transfer to the fluid, but with an hyperbolic limit in $1 / R_{\text {cond }}$; due to this limit, it makes no sense to use tubes as narrow as possible. In addition, this would convey to an increase of pumping power, which is exclusively proportional to cubic exponential of the inverse of the tubes diameter if the mass flow is considered constant - see Eq. (16), and so would diminish the net electric power produced by the power plant.

\section{Elements for linear receiver thermal optimization}

The foregoing analysis and numerical simulations of the thermal performance of linear receivers, and more specifically, of Linear Fresnel Reflectors receivers, point out the existence of an interesting design window at moderate values of the radiation flux impinging onto the selective coating of the receiver. These flux values are in the range from 8 to $25 \mathrm{~kW} / \mathrm{m}^{2}$, which is an average concentration level easily obtained by parallel Fresnel mirrors along the day. The radiation flux can be higher in the central tubes of the receiver, as seen in Fig. 3, but results of this work could be extrapolated for these values.

The width of the receiver, i.e. the transversal distance covered by the tubes of the receiver, is mainly fixed by the features of the concentrated solar beam coming from the Fresnel array, and it can be determined by the criterion of capturing $100 \%$ of all reflected photons at all relevant moments with sizeable sun power.

In this paper, the width was fixed to $49 \mathrm{~cm}$ in order to simulate the thermal interaction and response to low-quality concentrators; for obtaining a radiation of $25 \mathrm{~kW} / \mathrm{m}^{2}$ in a $49 \mathrm{~cm}$ wide receiver, the solar field would need to be around $20 \mathrm{~m}$ wide, which is the case of the Fresdemo plant $[41,42]$. In a given design, the concentrated radiation inherent aperture - which is affected not only by the natural aperture of the solar beam, but also by the tracking system and the mirrors quality - will be better known, and the transversal width of the receiver could be fixed more accurately.

The receiver's tubes diameter, $D$, which will fix the number of tubes for a given receiver width, and their length, $L$, for each receiver module are the design variables that must be fixed by applying the analysis formerly stated. Once the receiver is built, neither $D$ nor $L$ can be changed; however, the width of the receiver where radiation flux is impinging may vary along the day and the year, and some tubes should be closed at that time via valves. The main objective of this study is to establish appropriate criteria for determining the optimum diameter and length.

There are two parameters representing operational conditions: the concentrated radiation intensity and the inlet temperature of the fluid, although the latter is also a design parameter of the heat exchanger (heat carrier fluid - power block working fluid). The radiation intensity depends on the solar data, and also on the reflecting features of the array, while the inlet temperature is a value that can be managed to some extent by the plant operator, but only if the operating conditions of the thermodynamic cycle can undergo variations within some limits. In the project of a given plant, an operational range of values must be selected for each of these variables.

A last parameter representing operating conditions is the heat carrier fluid velocity inside the tubes. It is related to the temperature jump undergone by the fluid along the solar receiver, and it has a paramount importance in relation to the pressure drop and the pumping power associated to it. The outlet temperature has a great impact on the thermal performance of the CSP power plant: on the one hand, very high temperatures imply better efficiencies at the power block, represented in the exergetic efficiency by the Carnot coefficient; on the other hand, the higher the temperature, the higher the thermal losses. As a result there is a temperature range for maximum efficiencies that mainly depends on the radiation intensity; such temperature is obtained by varying the mass flow within the receiver. Recall that the radiation flux is not uniform, and so the different tubes of the receiver would have different thermal fluxes. This could be used for having different streams in different set of tubes depending on the thermal flux, thus optimizing the use of the energy.

A set of important facts and conclusions were derived from the previous analysis and discussions, in order to maximize the net power output of the hypothetical plant for given operating conditions. It has been shown that when varying the tubes diameter for given radiation intensities and receiver lengths, a maximum on exergetic efficiency is found. If tubes are narrower that such optimum value, pumping power become too important, the efficiency decreasing. If, on the contrary, the tubes are wider, the thermal process gets less effective, with the same result.

The optimum tubes diameter does not vary considerably when the radiation intensity does; this is good news for designing a linear Fresnel receiver module, because the choice of the tubes diameter and their length would be done regarding at an optimum configuration for the whole day, even though radiation intensity changes along the day and the year for linear Fresnel reflectors.

For this purpose, relevant information was presented in Fig. 12, where it can be seen that the exergetic efficiency goes down as the receiver unit becomes longer, particularly at low values of the radiation flux. This sets up the binding requirement for determining $L$. The optimum design choice is the use of narrow and relatively short tubes ( $1.4 \mathrm{~cm}$ diameter $-100 \mathrm{~m}$ long). The average thermal efficiency of a receiver working in the cited range of concentrated radiation (from 8 up to $25 \mathrm{~kW} / \mathrm{m}^{2}$ ) would be around $70 \%$ (Fig. 14), which seems a very suitable value for a very simple and robust CSP, and therefore much less expensive than other conventional alternatives. Nevertheless, it is of paramount importance to use the receiver configuration chosen in this work, and to follow the criteria established in the foregoing paragraphs of this section.

Additionally, a plant of this type would have a flexibility that could play an important role in the management of the plant. In particular, the operator could vary the inlet temperature and the fluid speed to modify the thermal output of the plant, if needed by any reason (for instance, a transient caused by a set of clouds). 
Information on the effects of these variations on the plant thermal output could be calculated as a part of the operating instructions.

Last but not least, it must be underlined that the maximum exergy efficiency is found at an outlet temperature which is higher for higher intensities of the radiation flux. To some extent this is an anticipated fact, because the outlet temperature has an important weigh in computing exergy, but it is an important hint in the sense that the optimum outlet temperature may not always be the maximum temperature allowed by the heat carrier fluid. In any case, having better Fresnel arrays producing more concentrated radiation fluxes, would have a positive effect on the overall energy output and efficiency of the plant.

\section{Conclusions and future work: a niche for cheap ways to exploit CSP}

Concentrated solar power development in last decade has consisted in Parabolic Trough Collectors similar to those installed in Mojave Desert during the 1980s and 1990s. This is mainly due to their maturity, which makes them a lower risk option. Nevertheless, currently built power plants are dealing with some problems that increase considerably capital and maintenance costs:

- The receiver is not fixed, and so rotating joints are necessary to follow the sun. High pressures and temperatures of the heat carrier oil can cause fluid leakages through these rotating joints, with negative effects on the environment and on the operators health.

- There must be metal-glass welds at the ends of each module of receiver tube, as a consequence of the vacuum between the selective coating and the tubular window. These welds are subject to failures along the collector life-time, and the corresponding $4 \mathrm{~m}$ long tube has to be substituted, with important economic consequences.

- The mass of materials (glass, steel, concrete, etc.) required for troughs is enormous. Taking into account the foundation of the pillars to support the receiver rotating structure, the weigh is around $250 \mathrm{~kg} / \mathrm{m}$. It is remarkable that a $50 \mathrm{MW}_{\mathrm{e}}$ (without thermal storage) typically has $60 \mathrm{~km}$ of trough modules, and requires more than 6000 tonnes of steel, i.e. an amount of steel larger than that of a $1000 \mathrm{MW}_{\mathrm{e}}$ nuclear power plant.

These problems have conveyed to research in other technologies, with the main objective of reducing costs on CSP. Linear Fresnel reflectors arise as one possibility with a great potential for cost reductions, thanks to its fixed receiver, with no need for vacuum and, therefore, no need for metal-glass welds, and with cheaper mirrors installed on lighter structures.

Nevertheless, linear Fresnel reflectors achieve lower average concentration ratios, and vary a lot along the day and the year. In addition, reflected beams from the furthest mirrors must travel a long distance until impinging onto the receiver, and so deviations due to the angular intensity distribution across the sun's disk, as well as to tracking and reflecting errors, imply the need of large receivers. As a consequence, Fresnel receivers designed until current time consisted on a secondary reflector and a tube with a large diameter; it has been seen in this work that the use of such receivers leads to very poor thermal performance. This fact has discouraged the development of this technology.

However, the use of a multitube receiver would increase greatly the thermal efficiency of the LFR, without having an important consequence in pumping power requirements. It has also been found a design window for these receivers, which is defined by the tubes diameter (in a range of $1-2.5 \mathrm{~cm}$ ) and their length (from $100 \mathrm{~m}$ to $300 \mathrm{~m}$ ). A deep study of this design window for a definite project

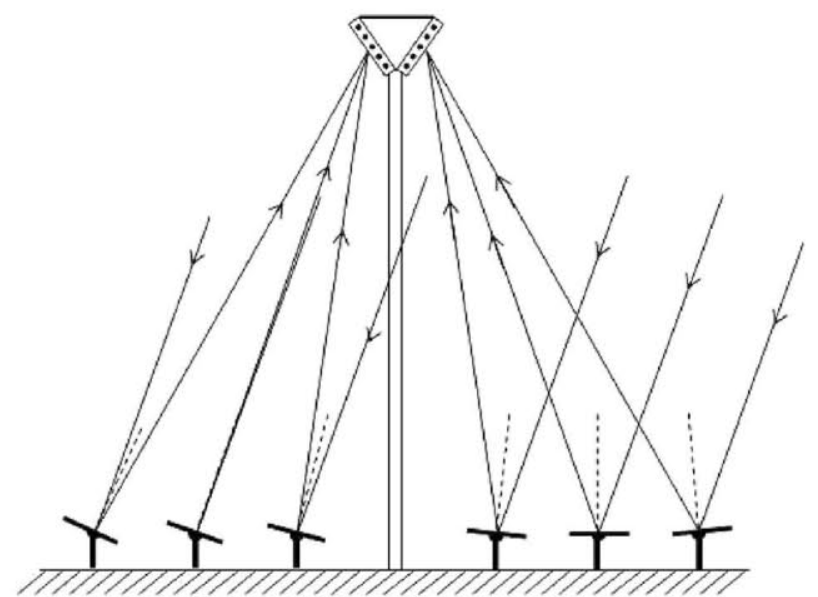

Fig. 19. A sketch of a LFR array with a dual receiver facing each half of the solar field.

will give the exact values for an optimum integrated thermal performance.

Multitube receivers have other advantages, such as the operational freedom for making flow more fluid by tubes where radiation intensity is higher and less by lateral tubes. Another operational mode would be the flow in series by different set of tubes, in the sense that periphery tubes can be devoted to preheat the fluid when going in one direction, flowing then by the central strip for the final heating up to the maximum temperature. In addition, as tubes are relatively narrow, thermal flux for each tube is more uniform that it would be for a unique large tube, hot spots being less important.

Future work in this field will address some transient analysis of the receivers; this includes effects produced by rapid variations of the concentrated radiation, and by thermal energy storage, which seems to be a very interesting complementary system for obtaining the best result of the collector along an integrated period $[43,44]$. Present work establishes the basis for future studies, where the optical and thermal processes will be coupled for a more accurate understanding of the process, taking into account the map of radiation flux.

This receiver must be coupled with mirror arrays able to provide radiation intensities in the range identified in this paper, at a minimum cost. Future research activities should work in this trend to advance properly in the learning curve for CSP, in order to get a significant reduction in the cost of electricity. In this new quest, an alternative on the position of the receiver should be studied at depth, for assessing the potential improvement in the optical connection between the mirror arrays and the receiver, as can be seen in the sketch of Fig. 19.

The receiver can be split into two halves, placed with some tilt angle from horizontal, so that the concentrated radiation impinges onto the receiver window glass with a small angle from normal incidence, which can improve the window transmissivity.

\section{Acknowledgments}

Discussions with the rest of our Research Group are highly recognized. Special thanks to "Fundación IBERDROLA", that has helped to this research with the Program "Energía para la Investigación".

\section{References}

[1] Quaschning V. Technical and economical system comparison of photovoltaic and concentrating solar thermal power systems depending on annual global irradiation. Solar Energy 2004;77(2):171-8. 
[2] Fernández-García A, Zarza E, Valenzuela L, Pérez M. Parabolic-trough solar collectors and their applications. Renew Sustain Energy Rev 2010;14(7): 1695-721.

[3] Duffie J, Beckman W. Solar engineering of thermal processes. 2nd ed. John Wiley And Sons; 1991 . ISBN:0-471-51056-4

[4] Kalogirou S. Solar energy engineering: processes and systems. Academic Press; 2009. ISBN:0-123-74501-2.

[5] Singh P, Ganesan S, Yádav G. Technical note: performance study of a linear Fresnel concentrating solar device. Renew Energy 1999;18(3):409-16.

[6] Mills D, Morrison G. Compact linear fresnel reflector solat thermal powerplants. Solar Energy 2000;68(3):263-83. ISSN:0038-092X.

[7] Odeh S, Behnia M, Morrison G. Performance evaluation of solar thermal electric generation systems. Energy Convers Manage 2003;44(15):2425-43. ISSN:0196-8904.

[8] Kalogirou S. Solar thermal collectors and applications. Prog Energy Combust Sci 2004;30(3):231-95.

[9] Muñoz J, Abânades A, Martínez-Val J. A conceptual design of solar boiler. Solar Energy $2009 ; 83(9): 1713-22$.

[10] Mills D. Advances in solar thermal electricity technology. Solar Energy $2004 ; 76(1-3): 19-31$.

[11] Thirugnanasambandam M, Iniyan S, Goic R. A review of solat themal technologies. Renew Sustain Energy Rev 2010;14(1):312-22. ISSN:1364-0321.

[12] Muñoz J, Martínez-Val JM, Ramos A. Thermal regimes in solar-thermal linear collectors. Solar Energy 2011;85(5):857-70. ISSN:0038-092X.

[13] Segal A, Epstein M. Optimized working temperatures of a solar central receiver. Solar Energy 2003;75(6):503-10. ISSN:0038-092X.

[14] Zhang Y, Lin B, Chen J. Optimum performance characteristics of an irreversible solar-driven Brayton heat engine at the maximum overall efficiency. Renew Energy 2007;32(5):856-67. ISSN:0960-1481.

[15] Masterson KD. Selective surfaces for solar-thermal conversion. J Solid State Chem 1977;22(1):41-9. ISSN:0022-4596.

[16] Khan MKA. Technical note copper oxide coatings for use in a linear solar Fresnel reflecting concentrating collector. Renew Energy 1999;17(4):603-8. ISSN:0960-1481.

[17] Farooq M, Raja IA. Optimisation of metal sputtered and electroplated substrates for solar selective coatings. Renew Energy 2008;33(6):1275-85. ISSN:0960-1481.

[18] Grena R, Tarquini P. Solar linear Fresnel collector using molten nitrates as heat transfer fluid. Energy 2011;36(2):1048-56. ISSN:0360-5442.

[19] Valenzuela L, Zarza E, Berenguel M, Camacho E. Control concepts for direct steam generation in parabolic troughs. Solar Energy 2005;78(2):301-11. ISSN:0038-092X, iSES Solar World Congress 2003.

[20] Birnbaum J, Feldhoff J, Fichtner M, Hirsch T, Jöcker M, Pitz-Paal R, et al. Steam temperature stability in a direct steam generation solar power plant. Solar Energy 2011;85(4):660-8. ISSN:0038-092X, solarPACES 2009.

[21] Laing D, Bahl C, Bauer T, Lehmann D, Steinmann W. Thermal energy storage for direct steam generation. Solar Energy 2011;85(4):627-33. ISSN:0038-092X, solarPACES 2009.

[22] Solutia, Therminol Heat Transfer Fluid; 2011. <http://www.therminol.com/ pages/products/vp-1.asp>.

[23] Martínez-Val J. Thermal solar energy collector. Patent W02010/076350, Es 2 231576 , PCT/ES2009/000557; 2010.

[24] Dang A. Concentrators: a review. Energy Convers Manage 1986;26(1):11-26. ISSN:0196-8904.
[25] Choudhury C, Sehgal $\mathrm{H}$. A fresnel strip reflector-concentrator for tubular solarenergy collectors. Appl Energy 1986;23(2):143-54. ISSN:0306-2619.

[26] Negi B, Mathur S, Kandpal T. Optical and thermal performance evaluation of a linear fresnel reflector solar concentrator. Solar Wind Technol 1989;6(5):589-93. ISSN:0741-983X.

[27] Goswami R, Negi B, Sehgal H, Sootha G. Optical designs and concentration characteristics of a linear Fresnel reflector solar concentrator with a triangular absorber. Solar Energy Mater 1990;21(2-3):237-51. ISSN:0165-1633.

[28] Singh PL, Sarviya R, Bhagoria J. Heat loss study of trapezoidal cavity absorbers for linear solar concentrating collector. Energy Convers Manage 2010;51(2):329-37. ISSN:0196-8904.

[29] Singh PL, Sarviya R, Bhagoria J. Thermal performance of linear Fresnel reflecting solar concentrator with trapezoidal cavity absorbers. Appl Energy 2010;87(2):541-50. ISSN:0306-2619.

[30] F.-C. Software. Engineering Equation Solver (EES); 2010 . <http:/l www.fchart.com/ees>.

[31] Forristall R. N.R.E.L. (US), Heat transfer analysis and modeling of a parabolic trough solar receiver implemented in engineering equation solver. Citeseer; 2003.

[32] Dudley V, Kolb G, Mahoney A, Mancini T, Matthews C, Sloan M, et al. Test results: SEGS LS-2 solar collector. Tech. Rep., Sandia National Labs., Albuquerque, NM (United States); 1994.

[33] Moss T, Brosseau D. Final test results for the Schott HCE on a LS-2 collector. SAN2005-4034, Sandia National Laboratory.

[34] Gnielinski $V$ et al. New equations for heat and mass transfer in turbulent pipe and channel flow. Int Chem Eng 1976;16(2):359-68.

[35] Incropera F. Fundamentals of heat and mass transfer. 6th ed. Danvers, USA: John Wiley \& Sons; 2007.

[36] Mott R, Noor F, Aziz A. Applied fluid mechanics. 6th ed. New York: Prentice Hall; 2006.

[37] Kumar S, Mullick S. Wind heat transfer coefficient in solar collectors in outdoor conditions. Solar Energy 2010;84(6):956-63. ISSN:0038-092X.

[38] Sandia NL. National solar thermal test facility; 2011. <http://www.sandia.gov/ Renewable_Energy/solarthermal/NSTTF/salt.htm>.

[39] Nayyar M, King R, Crocker S. Piping handbook. McGraw-hill; 2000.

[40] Abbas R, Montes MJ, Piera M, Martínez-Val JM. Solar radiation concentration features in linear Fresnel reflector arrays. Energy Convers Manage 2012;54(1): 133-44. ISSN:0196-8904.

[41] Bernhard R, Laabs H, De Lalaing J, Eck M, Eickhoff M, Pottler K, et al. Linear Fresnel collector demonstration on the PSA, Part I - design, construction and quality control. In: 14th International SolarPACES symposium on solar thermal concentrating technologies, Las Vegas, USA; 2008

[42] Bernhard R, Hein S, De Lalaing J, Eck M, Eickhoff M, Pfänder M, et al. Linear Fresnel collector demonstration on the PSA, Part II - commissioning and first performance tests. In: 14th International SolarPACES symposium on solar thermal concentrating technologies, Las Vegas, USA; 2008.

[43] Montes M, Abãnades A, Martínez-Val J, Valdés M. Solar multiple optimization for a solar-only thermal power plant, using oil as heat transfer fluid in the parabolic trough collectors. Solar Energy 2009;83(12):2165-76. ISSN:0038$092 \mathrm{X}$.

[44] Rovira A, Montes MJ, Valdes M, Martínez-Val JM. Energy management in solar thermal power plants with double thermal storage system and subdivided solar field. Appl Energy 2011;88(11):4055-66. ISSN:0306-2619. 